\title{
UK proposes ban on smoking in cars carrying children
}

$\mathrm{T}$ he United Kingdom is joining a handful of countries in a nation-wide ban on smoking in cars carrying children.

The House of Commons approved an amendment to the Children and Families Bill 2013 allowing ministers to make it a criminal offence for drivers to smoke cigarettes in cars with children present. The amendment was passed Feb. 10 by a vote of 376 to 107 .

The ministers will now propose regulations to make the law a reality. The new law will likely get mentioned later this year during the Queen's speech the last hurdle before legislation.

Only five countries have implemented the ban at a national level: the United Arab Emirates, Cyprus, Bahrain, South Africa and Mauritius. In Canada, such laws are a jurisdictional concern, with 10 of 13 provinces and territories now outlawing smoking in cars carrying children. Quebec, Nunavut, and Northwest Territories are the outliers. In the United States, six states support a ban.

The UK bill was backed by 591 respiratory health professionals, who published a letter in the British Medical Journal on Feb. 7 urging MPs to pass the bill, and outlining the damage that second-hand exposure to cigarettes and smoke inhalation does to children and adolescents.

"There is strong evidence that shows exposure to smoke is harmful for children," says Nicholas Hopkinson, chairman of the British Thoracic Society Chronic Obstructive Pulmonary Disease Specialist Advisory Group. "We would expect to see health benefits pretty rapidly. It will make a big difference for child health."

Researchers at the Harvard School

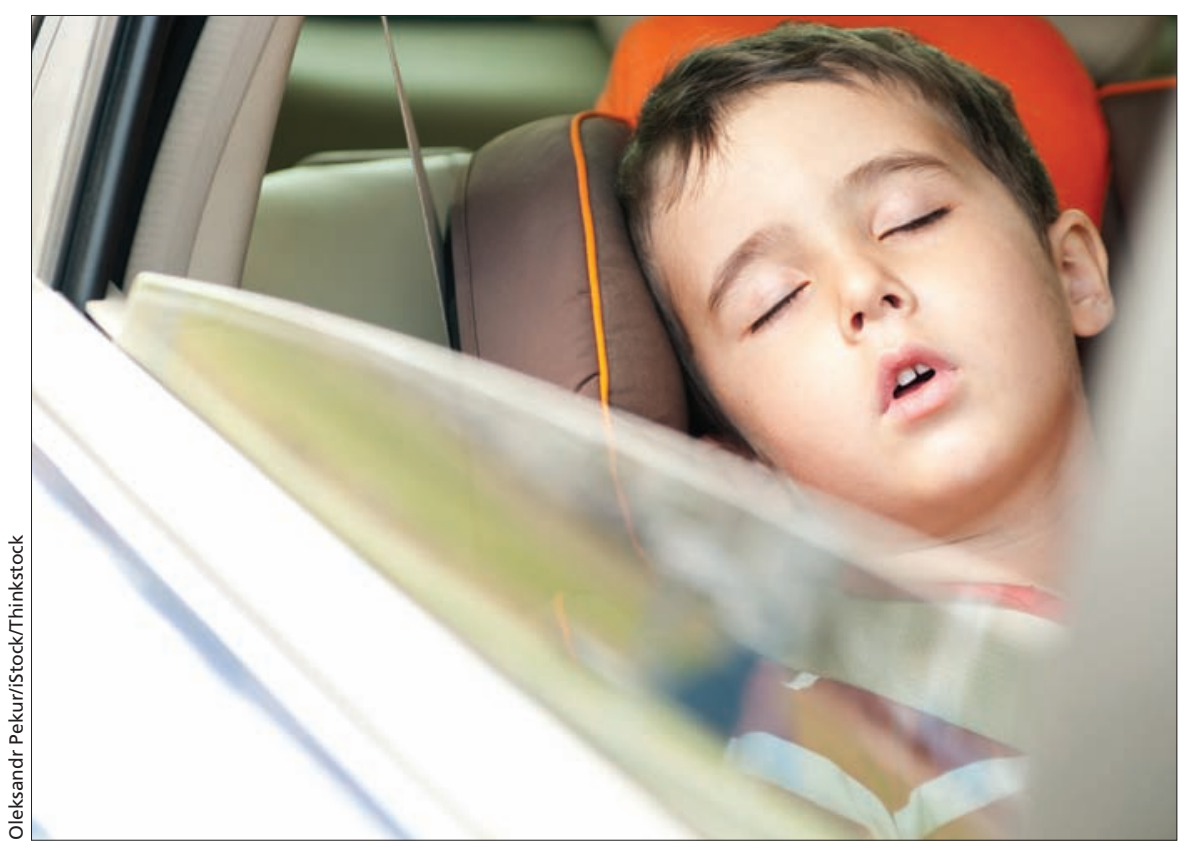

The bill to ban smoking in cars with children was backed by 591 respiratory health professionals.

of Public Health concluded that "alarming" levels of second-hand smoke were generated in just five minutes in vehicles under various driving, ventilation, and smoking conditions. Such airpollution levels pose a serious threat to a child's health from second-hand smoke in private cars under normal driving conditions, they concluded.

Those who oppose the bill often comment on the difficulty of enforcing the ban. "The best way of enforcing a smoking ban would be through selfenforcement - educating drivers about the health risks to the point where the perceived negatives outweigh the perceived benefits of lighting up," writes Neil Thorpe, a lecturer in transport studies, School of Civil Engineering and Geosciences, Newcastle University,
UK. Countries with the ban in place usually impose small fines on those who breach it.

But Hopkinson says the new UK law may net those who breach it fines or penalty points on their driver's license, but it will be self-policing from a social standpoint. "People can now challenge their friends and family who light up in cars with children because they are performing an illegal act."

"Legislation is what's required to change behaviour," added Hopkinson, "and evidence from similar legislation such as compulsory seatbelts and drunk-driving suggests that people will change when the bill becomes law." Neil Chanchlani MD, London, UK

CMAJ 2014. DOI:10.1503/cmaj.109-4736 